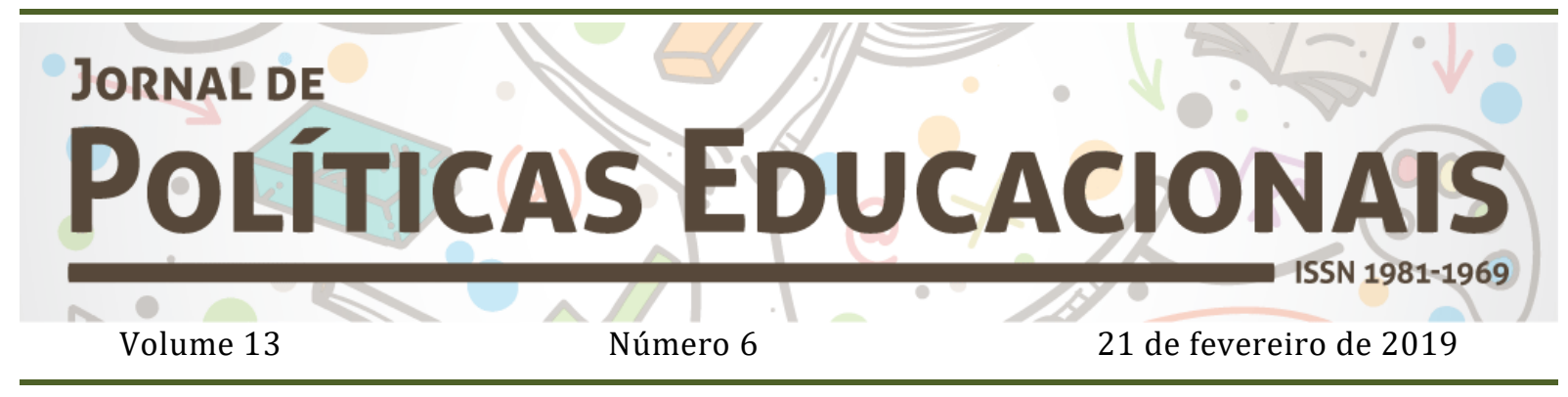

\title{
Sobre la política como ciencia. Educación, desarrollo legislativo y transformación de las sociedades contemporáneas
}

\author{
Sobre a política como ciência. Educação, desenvolvimento legislativo e \\ transformação das sociedades contemporâneas
}

\section{About politics as a science. Education, legislative development and transformation of contemporary societies}

Juan Luis Rubio Mayoral - Universidad de Sevilla ${ }^{1}$ Guadalupe Trigueros Gordillo - Universidad de Sevilla ${ }^{2}$

Citação: MAYORAL, J. L. R.; GORDILLO, G. T. Sobre a política como ciência. Educação, desenvolvimento legislativo e transformação das sociedades contemporâneas. Jornal de Políticas Educacionais. V. 13, n. 6. Fevereiro de 2019.

http://10.5380/ipe.v12i0.64424

\begin{abstract}
Resumen:
Este trabajo tiene como finalidad determinar los requisitos científicos que deben cumplir los estudios en Política y legislación educativa. Trata de contribuir a la resolución de los problemas de delimitación de objeto, concepto y método que como área de conocimiento tiene planteados y debe resolver. Para ello desarrolla un enfoque metodológico integrador aplicado a la investigación sobre el potencial transformador del sistema legislativo y el orden jurídico en materia de políticas en educación. Su objeto es analizar lo que han supuesto como parte de las políticas públicas para la transformación de las sociedades contemporáneas como mejora individual y colectiva al resolver en el plano normativo los temas más disputados como son los fines, modelos de sistema educativo y programas de acción.
\end{abstract}

Palabras clave: Estado; Política; Legislación; Educación; Epistemología.

Resumo:

\footnotetext{
${ }^{1}$ E-mail: jrubiomayoral@gmail.com

2E-mail: trigueros@us.es
} 
Este trabalho tem como objetivo determinar os requisitos científicos que os estudos em política e legislação educacional devem cumprir. Tenta contribuir para a resolução dos problemas de delimitação de objeto, conceito e método que como área de conhecimento tem levantado e deve resolver. Para tanto, desenvolve uma abordagem metodológica integrativa aplicada à pesquisa sobre o potencial transformador do sistema legislativo e o ordenamento jurídico das políticas educacionais. Seu objetivo é analisar o que eles assumiram como parte de políticas públicas para a transformação das sociedades contemporâneas como melhoria individual e coletiva, resolvendo as questões mais disputadas, como fins, modelos de sistemas educacionais e programas de ação no nível regulatório.

Palavras-chave: Estado; Política; Legislação; Educação; Epistemologia.

\begin{abstract}
:
The aim of this work was to determine the scientific requirements of studies about educational policies and legislation. It contributes to the differentiation of object, concept and method, which this field must solve. To this end, an integrating methodological approach applied to the research was developed about the transforming potential of the legislation and judicial order in terms of educational policies. The purpose was to analyse their impact as part of the public policies for the transformation of contemporary societies as individual and collective improvement when solving in the scope of regulations the most discussed topics, such as the goals, educational system models and action programs.
\end{abstract}

Key words: State; Policy; Legislation; Education; Epistemology.

\title{
Introducción
}

En la concepción política de Aristóteles [348-322 a.C.], el legislador debe ocuparse sobre todo de la educación de los jóvenes (Política, VIII, 1) pues donde no ocurre así, argumentaba que los regímenes resultan dañados, por ser preciso que la educación se adapte a cada uno de ellos, para preservarlo, modificarlo o establecerlo en origen, aplicando a la política la indagación ética para engendrar un régimen mejor. Dispondría de la potestad para establecer que los jóvenes formaran en todas las facultades humanas, en las artes y en la práctica necesaria de todas ellas para alcanzar la virtud. En su tarea normativa y reguladora, el legislador quedaba obligado a examinar si convenía confiar el cuidado de su educación a la comunidad o hacerlo de manera individual como ocurría entonces en la mayoría de las ciudades. Tras analizar el dilema, Aristóteles determina que, existiendo un fin único para toda ciudad, la educación debería ser necesariamente única y el cuidado de ella, común y no privado. Aparece la primacía de los derechos de igualdad sobre los de libertad de la persona, prevaleciendo la idea de una educación común regulada por los legisladores como bien público en pro de la polis.

Una idea que coincide con lo que avanzó Platón [427-347 a.C.] en el Libro VII de las Leyes, cuando señalaba a los legisladores la necesidad de reconocer en las normas, que todo hijo de vecino debiera recibir obligatoriamente formación, por pertenecer a la ciudad, más que a sus progenitores. Y para algunas materias ligadas a la defensa, mantenía que sería menester que sin diferencia de género toda la juventud fuera 
formada en ellas por maestros públicos que recibieran el sueldo de la ciudad. En buena medida, la confluencia de ideas en torno al sentido de la educación pública desde posiciones complementarias del pensamiento político clásico pueden ser el preludio de una investigación en la que confluyen el ser de la realidad con el deber ser de los ideales políticos. Se trata de una confluencia útil para poder hallar parte de las respuestas que es necesario avanzar para resolver alguno de los problemas y cuestiones fundamentales que aún subyacen al estudio de la Política y legislación educativa como parte de las atribuciones en las que la responsabilidad plena recae en el Estado a través de sus políticas públicas, que en su acción colectiva limita a la vez las libertades de la persona en educación.

En la realidad científica de la política y legislación educativa el problema es determinar con precisión que es lo que estudia y establecer cómo debe guiar ese esfuerzo por entenderlo. En la idea de Manuel de Puelles sería necesario resolver su indeterminación conceptual, establecer la naturaleza propia de sus saberes y solventar la ausencia de una delimitación canónica de sus campos de conocimiento (2013, p. 50) como problemas propios de todas las ciencias sociales. Se trata de una ciencia de objeto multiforme que ni en lo científico ni en lo político parece admitir una formulación precisa o unívoca. Por otra parte, su objeto se ha caracterizado por estar en un estado de indefinición permanente que incluye también el de los métodos para conocerlo. Se ha analizado la materia a través de su evolución haciendo inventario de sus corrientes y posiciones enfrentadas, tratando de delimitar su territorio, su identidad, sus fronteras. (KAUFMAN-OSBORN, 2006).

A pesar de su importancia, para poder investigar, para avanzar en el conocimiento, no es preciso encontrar una respuesta a estas cuestiones, por más que las evidencias epistemológicas muestren la necesidad de afianzar sus bases científicas y desarrollos metodológicos. El estudio de este extenso corpus de conocimiento conduce a un tema central y paradigmático para la materia. Se trata de la investigación sobre la transformación de las sociedades contemporáneas por medio del desarrollo legislativo que la acción política ha fraguado a través de la história en materia de educación pública. Aunque puede plantearse en sus consecuencias como algo obvio, no es un problema sencillo. En esta temática los enfoques analíticos empleados han sido de manera prioritaria los propios de la história aplicados al estudio de la política legislativa en materia de educación. Una perspectiva de notable importancia que puede servir de 
base para determinar una parte de los requisitos de carácter científico que deben cumplir los estudios propios de la Política y legislación educativa y a partir de ellos tratar de avanzar en la resolución de los problemas de objeto, concepto y método que como materia académica tiene planteados y debe resolver como área de investigación y conocimiento. La política es un hecho que va más allá de la esfera institucional del gobierno para involucrar a la mayor parte de los aspectos de la vida colectiva y personal.

\section{Estado, derecho y poder}

Investigar en Política y legislación educativa sobre bases capaces de proveer un conocimiento riguroso de los hechos requiere acotar los límites del objeto de estudio a fin de poder aplicar métodos de análisis apropiados. Si se restringe el objeto a las instituciones formales de gobierno con potestad legislativa es posible analizar el comportamiento de los actores individuales y colectivos que participan en ellas. En consecuencia, el Estado aparece como objeto central de investigación, siendo preciso vincularlo con los poderes independientes que lo constituyen, a través de la división clásica en legislativo, ejecutivo y judicial. El poder legislativo es ejercido por los Parlamentos para aprobar normas con rango de ley. Es en su proceso de génesis, donde reside parte de la pugna de ideas e intereses y la consecución de acuerdos entre los actores políticos que ostentan la representación de la soberanía nacional delegada por el pueblo. Esta dinámica cristaliza en un ordenamiento legal al que subyacen valores normativos que permiten realizar juicios sobre los procesos de génesis y el contenido legal (GERRING, 2006). Por su parte, el poder ejecutivo, permite al Gobierno, a través de la Administración General del Estado, gestionar los intereses públicos y ejercer la potestad reglamentaria en la aplicación y desarrollo de las leyes. La potestad jurisdiccional pertenece al poder judicial, responsable de juzgar y hacer ejecutar lo juzgado conforme a los principios de legalidad, independencia, unidad, exclusividad y responsabilidad. En su ejercicio puede alcanzar a establecer jurisprudencia, cuya materia es estudiada por la ciencia del derecho que tiene por objeto el estudio del conjunto de las sentencias de los tribunales, junto a la doctrina que contienen. Entre ellas destacan las sentencias interpretativas del Tribunal Constitucional o de aquellas instituciones responsables de defender la coherencia del sistema jurídico con la norma fundamental del Estado como una fuente necesaria para investigar en Política y legislación educativa. 
La delimitación básica del Estado como objeto de estudio permite apreciar los problemas para acotar su objeto tal como muestra su indeterminación conceptual ${ }^{3}$. Se recurre a la tradición anglosajona para tratar de discriminar sus múltiples facetas, pues en ella el término polity se utiliza para definir las actividades humanas que tienen que ver con el gobierno y con el concepto de Estado en sus diferentes formas, así como a la teoría política y al derecho público. Requiere un análisis de sus instituciones que están basadas en su constitución, en el ordenamiento jurídico y en la tradición. Por otra parte, se emplea la idea de politics para estudiar y definir la dimensión procedimental de mediar entre los conflictos de intereses, ideologías y valores a través del consenso. Sin embargo, el proceso continuo de elaboración de políticas y la mediación social no puede ser entendido únicamente a través de los contenidos de la dinámica política y la acción de sus actores. Sus contenidos, incluyendo sus metas, son descritos por el término policy, que remite a las actividades, a los programas de acción en los que sin duda subyace la ideología y el sentido particular de la politics, pero su realización depende de los intereses sociales, que pueden presentar notables variaciones en función de convicciones contradictorias e ideas enfrentadas, objeto de potenciales conflictos.

A nivel metodológico, existe la posibilidad de vincular como proyecto de estudio la idea de politics con la realidad del poder legislativo en relación a la génesis de normas a partir del la contienda y el enfrentamiento, de valores e intereses en conflicto, que en nuestra área de conocimiento quedaría identificada con la política de la educación. Por otra parte, la policy en tanto que programas de acción o políticas públicas, estaría vinculada al análisis del poder ejecutivo y tendría por objeto la acción política vinculada a al conocimiento de una realidad a través de la política educativa. El Estado como régimen y forma de gobierno en su conjunto respondería al sentido de polity.

Pero más allá de estas relaciones conceptuales el sentido latente es la noción de interdependencia entre el contenido de estos términos y esferas de conocimiento. Desde el análisis establecido a efectos epistemológicos necesitamos permear y desdibujar sus límites para ampliar la calidad del saber generado en el proceso de investigación de conceptos, poderes políticos y campos de conocimiento. Pues investigar en política de la educación no impide hacerlo en política educativa, al contrario, debido a que la acción como decisión política, y su programa, como guía de la acción, forman parte de la misma 
realidad que confluye y enriquece los estudios e investigaciones en Política y legislación educativa. Pero como disciplina científica es preciso que sea capaz de producir un conocimiento sistemático y neutral a efectos valorativos a pesar de que su objeto se desenvuelva en una continua entente entre intereses e ideas propias de la pluralidad humana (Arendt, 2008). Y ha de cumplir con una de las condiciones de validez de la ciencia que establece que para que los avances de conocimiento puedan alcanzar a ser universales y necesarios es preciso que sean aplicables a la realidad. En este punto no dejan de aparecer dudas sobre las diferencias que presenta como ciencia social el intento de naturalizarla su objeto, dada la complejidad de generar proposiciones de carácter axiomático a un ámbito sometido al carácter decisional de sus sujetos cuyo estudio carece del mismo grado de fiabilidad que los objetos de la ciencia natural. Sin embargo, como ciencia social debe establecer los hechos desde los que proponer alguna explicación y las categorías causales con las que trata de relacionarlos. A partir de ahí puede seleccionar los más pertinentes empleando los presupuestos del método positivo, y aunque sus conclusiones no puedan equipararse a las que son generadas desde las ciencias experimentales, sin embargo, pueden ser válidas y útiles desde la pluralidad de métodos de investigación que pueden ser empleados por las ciencias sociales para el estudio de un mismo objeto de conocimiento. Desde estas restricciones, es necesario plantear si la Política y legislación educativa debe abandonar todo intento de objetivar sus estudios e investigaciones ante la dificultad de lograr la total ausencia de valoración en sus conclusiones. La realidad muestra que se han intentado alcanzar conclusiones objetivables cuya fiabilidad puede valorarse en relación a su capacidad de generar un conocimiento sistemático, neutral a nivel valorativo, susceptible de verificación, y capaz de generar principios axiomáticos que permitan establecer previsiones (ARIAS, 2010, 80).

\section{Estado de derecho, valores e ideologías}

Aunque sometido a crítica y discusión, el positivismo jurídico trató de alcanzar ese fin. A efectos metodológicos puede emplearse las tesis iuspositivistas como modelo experimental de ensayo para nuestra disciplina. De este modo podríamos argumentar que si el objeto de la ciencia política es el Estado, por extensión ha de serlo el ordenamiento jurídico, lo que permite articular la estructura del conocimiento sobre las relaciones establecidas entre poder, política, legislación y educación, dando forma a un 
sistema de integración desde el que ensamblar las diferentes interpretaciones que modelan las caras de un prisma poliédrico. En la idea mantenida por Hans Kelsen [18811973] de que el estudio del derecho como sistema de normas que regulan la conducta recíproca de los hombres, ha de ajustar los datos de la realidad política, con las teorías y conceptos que permitan sistematizarlo e integrar los valores decantados por el transcurso de la historia (2010, 25-26). En esa concepción, el Estado carece de realidad sustancial previa o distinta al ordenamiento jurídico. Como tal no posee una entidad material, por lo que siguiendo los planteamientos de Immanuel Kant [1724-1804] habría de ser estudiado desde el conocimiento formal, que «se ocupa simplemente de la forma del entendimiento y de la propia razón, así como de las reglas universales del pensar en general, sin distinguir entre los objetos» (2010, p. 31). Por otra parte, su realidad material queda establecida en los hechos, por tanto, puede ser determinado como objeto de la experiencia. La legislación forma parte de la realidad social y es resultado de la acción política, por medio del poder legislativo, que confiere la potestad de elaborar, redactar y aprobar leyes. Entendiendo que el mandato de los poderes legislativos del Estado queda establecido en normas generales que poseen una validez objetiva por ser conformes a los principios que para la génesis legislativa establece el ordenamiento jurídico.

El estudio de las relaciones entre Política y legislación educativa gestadas a través de los poderes políticos del Estado, por su objeto y métodos, transforma la materia de investigación cuanto menos en una realidad compartida con las ciencias sociales, jurídicas e históricas. Su conocimiento depende, como el de otras realidades, del método científico adaptado a su objeto con que decidamos desarrollar el estudio. Desde aquí, es posible inferir que como disciplina científica ha de elaborar o compartir un conjunto de útiles y herramientas, aptas para el objeto que delimita su conocimiento. Es entonces cuando debemos determinar que parte del objeto vamos a estudiar, pues los métodos existentes provienen del conjunto de ciencias que han dado forma a la materia. Podemos situarnos en perspectiva histórica, sociológica, antropológica, jurídica, normativa o legal, política, económica, lógica, filosófica o metafísica, por citar una parte de las áreas que comparten el mismo o semejante objeto de conocimiento: el Estado. Pero es el analista quien ha de saber hacer uso de ellas y dosificarlas para lograr fórmulas y proporciones acordes con el objeto y enfoque que adopte la disciplina académica. Por otra parte, sus principios para ser universales y necesarios, deben servir 
para toda relación existente entre política y legislación cuidando que la base teórica que sustenta la construcción de la disciplina posea la suficiente capacidad para aislar e identificar todo lo que no sea propio del objeto de la Política y legislación educativa.

También intervienen los valores e ideas, sobre todo aquellos que defienden los actores de la política en pugna por el poder para hacer realidad sus aspiraciones en materia educativa. Como disciplina científica la posición no pasa tanto por eludir o asumir los valores de la política como por determinarlos. Más allá de su conocimiento, entre las posibles soluciones que adopte la política para establecer la acción, estas pueden basarse en la experiencia. Hay que entenderlas entonces como conocimiento relevante sobre el saber hacer, que es algo propio de la técnica y capaz de gestar principios que permitan guiar la acción. Pero para que la acción pueda llevarse a efecto en una comunidad política, el poder del Estado ha de estar en posesión de la capacidad de ejercer un dominio coactivo. El poder es prevalente al derecho como argumentaba Norberto Bobbio [1909-2004] sobre la idea de que «el derecho sin poder es vacuo» (1985, 21-22) lo que en realidad plantea una ligazón indisoluble que une poder, estado y sistema de derecho como componentes necesarios para el análisis de la política y legislación. Una realidad que le permitirá al Estado responder o adaptarse a prerrogativas externas e impedir la inobediencia interna, cumpliendo con la esencia de la política formulada por Carl Schmitt [1888-1985] también en materia de educación (2011) como puede apreciares entre otros casos, en el de las medidas de política educativa cuya finalidad era evitar la radicalización política o religiosa entre otras conductas no deseables a nivel de convivencia promovidas por ideologías extremas. Por tanto, Estado, legislación y poder político han de ser estudiados como componentes de los procesos de transformación social. De ello se infiere que a través del estudio de la génesis de la acción política en materia de educación es posible conocer los componentes de las políticas como respuesta a los problemas de la realidad sobre el principio al que tiende la política, encaminado a alcanzar la concordia, el acuerdo, el pacto, a fin de ordenar, preservar y perfeccionar la convivencia. La transformación impuesta por el poder político a través de las normas como consecuencia de la confluencia de conocimientos e informaciones y de la capacidad para implementarlos también deben satisfacer ciertas condiciones para ser válidas en la práctica social. 


\section{Legislación y sistema de derecho}

Por legislación se conoce la ciencia que tiene por objeto el estudio del cuerpo o conjunto de leyes y otras normas por las cuales se gobierna un Estado o una materia determinada. Son dictadas siguiendo los procedimientos establecidos para el ejercicio del poder legislativo en representación del pueblo soberano y en democracia suelen ser el resultado del debate de ideas que aspiran a transformar la realidad. El análisis de los mandatos que contienen son una parte posible de sus componentes. Pero tan sólo definen un fragmento de la realidad que como expresión del poder del Estado han dado forma a la sociedad, incluida su evolución y los cambios provocados en una parte extensa de sus cualidades y características culturales, económicas y políticas. El contenido del texto legal como tal nace de un acto de creación humana en el que media la invención, la concepción de ideas gestadas a partir de la proyección imaginada de una cosa deseable. La constitución de los parlamentos en regímenes no presidencialistas y la formación del gobierno tras la aplicación de las leyes electorales, hace que el desarrollo de sus políticas dependa del apoyo y la búsqueda de acuerdos sobre intereses comunes con el resto de formaciones. No obstante, es un principio que no se cumple en el caso de la obtención de mayorías absolutas.

Desde la ciencia del derecho, entendido como orden normativo o conjunto de leyes que regulan la vida de un colectivo humano organizado es posible analizar la relación entre el derecho y la política al menos desde una doble dimensión. La primera al entender que la acción política se hace efectiva a través del derecho, y la segunda, al concebir que el derecho, disciplina y establece los límites de la propia acción política (BOBBIO, 2009, 254). Para el derecho positivo el poder de quien tiene la fuerza en una nación hace las leyes (HOBBES, 1992,10) y lo que lo caracteriza como comunidad política es el principio de soberanía, la legitimidad social, la autoridad normativa y el ideal de justicia con el que han de concordar sus leyes. Pero la génesis y aplicación de las normas son susceptibles de ser interpretadas desde los motivos que las justificaron lo que incluye la validez y la efectividad de las normas del sistema. También supone que en la relación entre derecho y poder sea preciso determinar, desde una nueva perspectiva, si quien lo detenta tiene el derecho de tenerlo y lo ejerce en coherencia y dentro de los limites de las normas establecidas en la idea de Estado de Derecho. Una idea que más allá del sentido restringido que subordina el poder político al derecho, propone identificarlo con la existencia de un orden normativo cuyas disposiciones, como destino 
de todo grupo político, son necesarias para la supervivencia por lo que se hacen valer de forma coactiva y caracterizan y diferencian a ese grupo social (BOBBIO, 2009, 259).

\section{Transformar la realidad}

En el pensamiento de Hanna Arendt, la base de la política parte de la pluralidad de los hombres como hecho, y trata, del estar juntos los unos con los otros; de los diversos. Y es algo que nace, en términos de la filósofa, del Entre-los-hombres, y por tanto fuera del hombre (2008, pp. 45-46). Por ello la política puede ser interpretada como una actividad propia de los humanos por la que se organizan en sociedad mediante la creación de normas de convivencia que persiguen objetivos compartidos por la comunidad. Esa confluencia garantiza la validez de un procedimiento de producción legislativa y alcanza legitimidad en la idea de Jürgen Habermas cuando logra el acuerdo de los ciudadanos por medio de los procesos participativos reconocidos en el ordenamiento jurídico (2004). En los modelos liberales de democracia, el proceso constituyente se transformó en decisivo para el Estado de Derecho pues en su contenido quedaban reconocidas las opciones de la sociedad, que representadas a través de la política se trasladaron a la norma fundamental a la que quedaban vinculadas los principios y valores que deberían cumplir las normas ordinarias o derivadas que la desarrollaran. En la mayoría de casos provienen de la evolución histórica de la sociedad y adquieren eficacia como norma jurídica. La ley fundamental se transforma en base de un conjunto de normas generales que dan forma al Estado dotándole de un régimen político, de una organización territorial, y de unos vínculos con la ciudadanía. En las democracias occidentales no se puede prescindir de un momento originario en el que los valores de una sociedad y los principios que la estructuran integran la política y la legislación aportando una dimensión necesaria a las restricciones de las teorías positivistas. La idea moderna de Constitución surge en el contexto liberal donde prima el individuo sobre la sociedad, aunque su contenido garantiza los derechos fundamentales y libertades públicas sobre un modelo de basado en el principio de división de poderes. Una condición que tal como estableció el Art. 16 de la Declaración de derechos del hombre y del ciudadano (1789) era necesaria para adquirir su, pues «una sociedad en la que no esté asegurada la garantía de los derechos ni reconocida la división de poderes, no tiene Constitución». 
En la pluralidad humana, que es base de la política, una parte de la sociedad siempre necesitará la acción del Estado frente a aquella que para preservar sus privilegios postula su no intervención desde la prevalencia de los principios de libertad negativa. Aunque a los Estados les corresponde respetar los principios de libertad han de velar por la aplicación imparcial del sistema de derecho impidiendo que surjan posiciones de dominio que vayan en contra de la igualdad de oportunidades o que aminoren las libertades. El Estado americano constituido tras la declaración de independencia en 1776, y la guerra contra Gran Bretaña, se desarrolla a partir de la Constitución federal de 1787, por la que se crean los Estados Unidos de América del Norte. En Europa, la Declaración de los derechos del hombre y del ciudadano de 1789 supondrá una amenaza para la autoridad moral y las formas políticas tradicionales por la extensión del nuevo concepto de derechos universales. Además del pensamiento ilustrado, otros autores, como Thomas Payne [1773-1809] respondieron a las posiciones conservadoras, como las defendidas por Edmund Burke [1729-1797] en Reflexiones sobre la Revolución francesa (1790) a través de su obra Rights of Men (1791). En ella Payne formuló tres de los principios o leyes del orden natural que establecen la base de la convivencia social y de la política. El primero postulaba que los hombres han nacido y continuarán siempre, libres, iguales con respecto a sus derechos y que las distinciones civiles sólo se pueden basar en la utilidad pública. El segundo estableció que el fin de toda asociación política era la preservación de todos los derechos, naturales e imprescriptibles del hombre, siendo estos los de libertad, prosperidad, seguridad y resistencia a la opresión. El tercero determinaba que la Nación era la fuente de toda soberanía y que ninguna persona o ningún grupo, podría adjudicarse una autoridad que no derivara expresamente de ella. En Europa, estos principios reconocidos por el movimiento ilustrado, empeñado además en llevar las Luces al pueblo, serán parte de los ideales que la Revolución Francesa traslade al modelo de Estado liberal a través de sus distintas Constituciones. En el sistema teórico del liberalismo, a la nación, se le reconocía la soberanía, en sustitución del monarca absoluto, y el derecho a establecer leyes fundamentales junto a un modelo electoral que con el trascurso del tiempo alcanzó a ser representativo y universal. 


\section{Estado, enseñanza pública y progreso social}

La extensión de los sistemas nacionales de enseñanza es una característica de los modelos de Estado surgidos a partir de las revoluciones liberales que marcaron el inicio de la edad contemporánea. Es sobre todo en el Titulo I de la constitución francesa de 1791 dedicado a garantizar los derechos naturales y civiles en la que se reconoce la obligación del Estado para prestar a los ciudadanos una instrucción pública común y gratuita en aquella parte indispensable y con ello la ampliación de las bases para acceder a la cultura, haciendo realidad los derechos de igualdad en coherencia con la soberanía nacional que se atribuye al Estado. Los principios de libertad, se extienden al pensamiento, prensa e imprenta, asociación, circulación, creación, o producción entre otros. Asume las funciones ligadas al reconocimiento del derecho a la educación y será el responsable de extender, controlar y supervisar la enseñanza de las sociedades. Pasa a detentar el poder en educación y por tanto la posibilidad de ejercer un dominio coactivo basado tanto en la posesión de determinados bienes, la determinación de sus conocimientos, y los instrumentos de fuerza que coadyuvan a su consecución. Elementos que en la idea de Max Weber [1864-1920] se identifican con los poderes económico, ideológico y político propios del poder del Estado (2014, pp. 127-186). La educación como señalábamos al comienzo es un elemento de legitimación, aunque el cambio en la dinámica del poder también forma parte de sus funciones como señalaba Aristóteles. Más tarde, Pierre Bourdieu desarrolla estas ideas para señalar que ocupa un lugar importante dentro de la labor colectiva que debe hacer el Estado para lograr la construcción de la nación. De manera que al territorio regulado por la legislación es preciso unir la creación de su ciudadanía, ligada al Estado y a la vez entre sí por un conjunto de derechos y deberes (2014, p. 14). En este sentido, tal como lo define en Homo academicus (1984), el Estado es considerado como un «metacampo» en que las luchas entre los sectores que lo constituyen tienen como objeto determinar la posición que cada uno debe ocupar legítimamente en relación a los otros (2014, p. 273).

Una de las contradicciones del Estado liberal surge de la paradoja entre sus ideales y la realidad de sus pactos y cesiones frente a los intereses de las diferentes fuerzas políticas y sociales. Entre ellas la aspiración a la escolarización universal y las resistencias que hubo de enfrentar, en especial las que planteó la Iglesia católica en torno a la posición de supremacía que ocupaba en su relación con el Estado y con su papel en la educación del pueblo. Los establecimientos de enseñanza, en una parte 
importante, se habían mantenido bajo la iniciativa eclesiástica debido, entre otras razones, a la limitada parte de la sociedad a la que afectaba esta actividad y también a la legitimación que como institución social prestaba al propio gobierno. Entre las ideas liberales figuraba la consideración de la enseñanza como una prioridad nacional que por diferentes razones de orden político y práctico conducirían a la extensión de sistema publico nacional a la mayor parte de la población. Entre otras razones por la falta de capacidad y voluntad del sistema privado de universalizar la enseñanza elemental. Una de las razones fundamentales de ese impulso reside en la naturaleza del Estado nacional que se formó en el siglo XIX europeo. En Francia en el verano de 1789 las clases modestas, rebeladas contras las exacciones del Estado del Antiguo Régimen dejaron de pagar impuestos. Gabriel Tortella explica que la Asamblea Constituyente, ante la imposibilidad de recaudar, decidió que era preciso confiscar los bienes de la Iglesia para saldar la deuda pública a través de su venta. A los que se unieron las propiedades y bienes de la nobleza que había abandonado el país junto a la que fue encausada por actividades contrarias a la revolución (2005, p. 52). Tras la enajenación de bienes las prestaciones sociales de la Iglesia en materia educativa se extinguieron. Entre ellas la enseñanza. A partir de la aprobación del texto constitucional de 1791 el Estado se comprometió a prestar educación a través de «una instrucción pública, común a todos los ciudadanos, gratuita respecto de aquellas partes indispensables para todos los hombres». Pero en esa declaración reconocía las diferencias que se mantendrán en la realidad entre una educación popular de carácter elemental y gratuito y una educación media y superior destinada a las clases sociales mejor situadas en lo económico, cultural y político. Una evidencia coherente con las diferencias que subyacen a los derechos derivados del principio de igualdad, pues al promoverlos, el Estado viene a reconocer de manera implícita la existencia de diferencias. Un hecho que impone un trato diverso en relación a las desventajas, a fin de alcanzar la equidad. No obstante la iniciativa del Estado fue la que transformó a la educación en derecho social derivado de los principios de igualdad y libertad en sus diversas manifestaciones. Su confluencia cristalizó más tarde en torno a la idea de igualdad de oportunidades no sólo en el acceso, también al reconocerla en las diferencias situadas en las bases de partida. Primero ante la educación elemental que será obligatoria y gratuita, y más tarde se ocupará de la igualdad de acceso en los niveles postobligatorios en función del mérito y la capacidad de la persona, facilitando con ello la igualdad de acceso al conocimiento. 
En España, la monarquía constitucional reconocía en el texto de 1812 la creación de escuelas de primeras letras en todos los pueblos para enseñar a los niños a leer, escribir y contar, pero también para que fueran formados en el catecismo de la religión católica y a una exposición breve de las obligaciones civiles. La obligatoriedad de esta enseñanza entre los seis y los nueve años se inicia a partir de la promulgación de la Ley de 1857, si bien la falta de medios del Estado lleva al legislador a establecer que tal derecho podría ser satisfecho en el domicilio por los padres o ser proporcionado por establecimientos particulares. De hecho, el Código Civil español de 1888 determinó como obligación de los padres el instruir a sus hijos en relación a su fortuna. No fue hasta 1931 cuando la Constitución de la República en su artículo tercero estableciera la obligatoriedad y gratuidad de la enseñanza primaria.

Para consolidar los logros de la revolución política, los estados liberales emprendieron a lo largo del siglo XIX una expansión comercial, económica y colonial que engendrará la primera revolución industrial basada en la incorporación de la ciencia a la realidad mediante las tecnologías. Primero del carbón y el acero y más tarde de la química del carbono y de la electricidad con el desarrollo de las aplicaciones de la revolución de la física de la segunda mitad del siglo XX. Desde ella surgirán las revoluciones científicas relativista, cuántica y biológico-molecular. A nivel mundial, la evolución de los sistemas de creación de conocimiento y transferencia tecnológica marcaron el desarrollo de las potencias emergentes en los comienzos del siglo XX alcanzando sus puntos álgidos en las revoluciones políticas que desencadenó la Gran Guerra de 1914-18. Entre ellas, la revolución bolchevique de 1917, la extensión de los derechos sociales incluidos en la Constitución de Weimar, junto a la crisis de las democracias occidentales y sus sistemas económicos tras el Crack de 1929. Hechos que favorecieron el ascenso de los totalitarismos y el estallido de un nuevo conflicto en Europa que acabaría transformándose en la II $\stackrel{a}{a}$ Guerra Mundial. Serían los sistemas de ciencia y tecnología creados para ganar la guerra en el terreno militar los que más tarde modelaron una parte de la realidad social al aplicarse al terreno civil. A la componente política de la educación se unió la económica desde la perspectiva del trabajo como factor de producción y de la técnica como elemento condicionante. Sin duda esta última dependiente del desarrollo de la ciencia básica y de las capacidades para ser transferida a la producción de bienes. El sistema educativo pasó entonces a transformarse en elemento estratégico de los modernos Estados liberales obligados para su permanencia 
a extender las libertades a la vez que a proteger el modelo de democracia. El reconocimiento de la educación como derecho social, en su proceso de formación, alcanza sus mayores niveles de prestación avanzado el siglo XX en el modelo de Estado de Bienestar. La escolarización plena de la población, se hizo obligatoria y gratuita, ampliándose el número de años de permanencia en el sistema escolar y los contenidos de conocimiento que formarían parte del proceso de enseñanza y aprendizaje. Se cumplía así con el derecho de prestación universal que exigía el compromiso activo del Estado en la extensión y el acceso a la educación pública junto a la sanidad y la seguridad social entre otros. Las sucesivas crisis económicas iniciadas en el último tercio del siglo XX limitaron las capacidades financieras del Estado y con ello el modelo de bienestar. En educación la demanda de calidad, libertad de elección de centro docente y autonomía institucional pasaron a ser los argumentos de las posiciones neoliberales.

\section{Limites de la acción del Estado}

En medio de las corrientes liberales e individualistas, Wilhelm von Humboldt analizó los límites de la acción del Estado frente a la persona postulando que las libertades propias de la heteronomía social eran las que imponían los límites a la autonomía individual, facilitando la coexistencia de los derechos de libertad individual con los de igualdad social. En educación manifestaba la necesidad para el género humano, por una parte de mantener el nivel de cultura alcanzado y por otra, de avanzar desde ella mediante la formación de los individuos. Pero defiende que el Estado no debe imponer una única formación pública, dado que imprime en la persona una forma política en la que por una parte «prevalece siempre el espíritu del gobierno» y por otra es ineficaz, pues no consigue la «reforma de las costumbres» de acuerdo con las pautas del Estado». Llegará a proponer la posibilidad de «imponer tutores a los padres negligentes o ayudar a los padres pobres» como alternativa al monopolio de la enseñanza por el Estado (2009, 64-65). En democracia, en el continuo que representa la búsqueda de un equilibrio entre los derechos de libertad e igualdad no es coherente aminorar los principios que de ellos se derivan. Perjudicar los derechos de libertad supondría transformarla en apariencia, y disminuir la eficacia del principio de igualdad sería ir contra la igualdad en el sufragio y el reconocimiento del poder soberano por lo que puede carecer de sentido práctico contraponer ambos derechos. 
La desregulación en la prestación de derechos que eran atribución del Estado liberal se transforma en desposesión democrática en la idea de Luc Ferry desde la tesis de que los modelos democráticos aspiran a la autonomía de la persona, a que cada ciudadano sea fiel a la idea de libertad esbozada por Rousseau de obedecer a la ley que cada persona se da a si misma, actualizada a la sociedad transhumanista y a los modelos de economía colaborativa que enlazan con los principios del liberalismo individualista y democrático. Al Estado se le pide como solución que actúe por medio de la regulación, que ponga límites a la lógica del individualismo en medio de una realidad social globalizada en la esfera económica, científica y técnica que supera los límites de acción de las políticas públicas limitadas a las esferas estatales y nacionales (2017, pp. 157158). El neoliberalismo además, ha logrado hacer del rendimiento individual un canon que permite transformar la realidad. En la interpretación de Byung-Chul Han, estas premisas han provocado que cada cual se ejerza en su persona como amo y esclavo llevando la lucha de clases del plano colectivo al individual al transformarlo en una lucha personal e interna consigo mismo. La evolución capitalista del modelo neoliberal «transforma la explotación ajena en la auto explotación que afecta a todas las "clases"», siendo la persona fracasada quien se vuelve contra sí misma, quien no se acepta, se rechaza, se tacha, inútil o incapaz. Al ser valores admitidos por la sociedad se sitúan por encima del individuo impidiendo que surja resistencia colectiva alguna contra el sistema (2014, pp. 17-18).

En materia de Política y legislación educativa los ciclos y turnos de poder hacen que las ideas definan los programas de acción política alterando los sistemas educativos por medio de reformas legislativas. En este sentido es posible que la historia de las revoluciones liberales pueda ser empleada como uno de los mejores ejemplos para demostrar este aserto. Cuando Emile Durkheim, tras dar cuenta del contexto revolucionario en que surgieron las Escuelas Centrales, describe su involución con Bonaparte, da cuenta de que el 11 floreal del año X fue votada una ley que las suprimió y que a la vez «redujo a la nada la pedagogía revolucionaria» (1982, p. 378) dando pábulo a Julius von Kirchmann cuando afirmaba que bastaban algunas palabras del legislador, para reducir a basura bibliotecas completas (1949). Una realidad semejante a la que describía también Miguel de Unamuno cuando identificaba la política educativa hispana con «ese tejer y destejer desde el ministerio la tela de Penélope de nuestra enseñanza oficial» (2007, p. 29), En la actualidad Manuel de Puelles habla de «inestabilidad 
legislativa, y del cansancio que provoca en la comunidad educativa, no exento de un alto nivel de desmoralización y fatiga de profesores y agentes sociales que genera escepticismo hacia las reformas por más que se plateen desde los poderes del Estado como el medio optimo para alcanzar la mejora de los sistemas de enseñanza ( 2016, p. 17).

\section{Conclusiones}

El poder político genera el ordenamiento jurídico que da forma al Estado a partir de una ley fundamental. Los poderes ejecutivo y judicial completan la estructura de la realidad normativa que moldea las acciones reguladas por el Estado en materia educativa permitiendo integrar enfoques y corrientes heterogéneas. Sin duda es preciso asentar la relación entre Estado, política, poder y norma jurídica, pues el derecho no puede concebirse sin el poder desde el que se creó y que lo mantiene. Es el que da forma al Estado desde el positivismo formal, cuyos postulados lo identifican con el conjunto de normas que operan en un territorio determinado sobre una población.

La educación es una realidad de interés necesario y de consecuencias extraordinarias de la que forma parte la política de la educación desde las acciones en educación por medio de normas legales que son expresión y tienden a modelar la realidad de la educación para un territorio y una población que constituyen un Estado. La ciencia política como ciencia del Estado permite injertar la política de la educación para que fructifique a partir de la metodología científica y de sus categorías lógicas y paradigmas. Y ha de ser consecuente con las condiciones que como fenómeno social mantiene la realidad sujeta a la sucesión y concatenación de hechos sometidos como tales al principio de causalidad que ha de ser comprendido y explicado, más allá de la concatenación de hechos que la componen. Es complejo por tanto que la Política y legislación educativa pueda cumplir con los principios de la ciencia positiva por lo que no está demás señalar que entre esta posición y la «narratividad» propuesta como alternativa por otros enfoques, exista un «terreno intermedio» que a modo de «ciencia blanda», es identificado «con el tratamiento sistemático de los problemas y el uso de un lenguaje especializado» en el que se podría distinguir la existencia de una ciencia política empírica y una teoría normativa basada en su calidad y rigor antes que en la contrastación real de sus postulados (ARIAS, 2010, p. 87). Por su parte, el Estado como ordenamiento jurídico nutre a la legislación educativa con los elementos propios del 
derecho como rama o especialidad de la disciplina jurídica dedicada al estudio de una parte o sector del ordenamiento jurídico. Esta relación no resuelve todos los problemas de la materia, pues como indicaba Immanuel Kant, el conocimiento histórico de determinadas normas jurídicas o de determinadas formas políticas no puede conducir a un conocimiento de qué es el derecho o el Estado (2012, pp. 38-39). En consecuencia, se aprecia una necesidad de hacer uso también de otras ciencias sociales, pues el estudio de la historia de la legislación educativa o de las formas de gobierno o Estado que las gestó, no garantizaría su carácter científico.

Sin duda, son numerosos los problemas educativos que reclaman respuestas desde el propio devenir de la realidad. Sus soluciones van desde las posiciones liberales individualistas basadas en la primacía de los derechos de libertad, a las sociales ligadas a los derechos de igualdad. Una dicotomía cuyo equilibrio o concordia nos conduce al debate clásico entre individualismo y universalismo cuyas consecuencias es preciso investigar en su proyección en la realidad. Es esa evidencia la que reclama ser investigada desde los diferentes estados, ideologías, o culturas, y es la que señala la necesidad de hacerlo también sobre su influencia en grupos, etnias, minorías sociales, desplazados, excluidos y también en las distintas confesiones y creencias, para crear una base sólida de conocimientos, un marco de experiencias en investigación básica en Política y legislación educativa que nos ayude a clarificar y hallar respuestas a los interrogantes que constituyen los hechos de la realidad.

Como toda intervención del Estado limita la autonomía de la acción de manera heterónoma, las normas positivas en materia de educación, aunque restringen la libertad de las acciones del individuo, aportan soluciones y evitan conflictos al ser imperativas y coactivas en su cumplimiento. Determinan el porvenir de individuos y sociedades que pasan a depender de los fines que guíen el desarrollo de las políticas públicas en educación, junto a los que definen el sistema de investigación científica, desarrollo e innovación. La ventaja comparativa puede basarse en contar con un amplio acuerdo de las principales fuerzas que ordenan la sociedad civil para articular un modelo capaz de adaptarse con eficacia y eficiencia a las necesidades impuestas por los cambios en el conocimiento y su transferencia a la sociedad sin abandonar las exigencias de la justicia y la equidad en coherencia con otras normas, costumbres, creencias y valores que condicionan el devenir de cada una de las sociedades. Frente a las limitaciones ideológicas y fácticas del poder, Hans Kelsen defendía que debía imperar la 
ciencia, pues el conocimiento positivo necesita para progresar un modelo de libertad que no depende sólo de su independencia respecto a cualquier tipo de influencia política, sino también de que exista libertad dentro de la ciencia pues uno de sus atributos es la tolerancia. Un principio de libertad negativa que forma parte de las raíces primigenias sobre las que eclosionó la ciencia política, y que necesita estar mediado por una idea de justicia que podría darse en aquel orden social bajo cuya protección pudiera progresar la búsqueda de la verdad, en libertad, paz y democracia (2008, p. 63).

\section{Bibliografía}

ARENDT, H. ¿Qué es la política?, Barcelona: Paidós, 2018.

ARENDT, H. La promesa de la política. Barcelona: Paidós, 2008.

ARIAS MALDONADO, M. La ciencia equívoca. Sobre el estudio científico de la política. RIPS, Vol. 9, núm. 2, 2010, pp. 75-89.

BIRKLAND, Th. A. An Introduction to the Policy Process. Theories, Concepts, and Models of Public Policy Making. Londres: Routledge, 2016.

BOBBIO, N. Origen y fundamentos del poder político. México: Grijalbo, 1985.

BOBBIO, N. Teoría general de la política. Madrid: Trotta, 2009.

BOBBIO, N. Iusnaturalismo y positivismo jurídico. Madrid: Trotta, 2015.

BOURDIEU, P. Sobre el Estado. Cursos en el Collège de France (1989-1992). Barcelona: Anagrama, 2014.

BOURDIEU, P. Homo academicus. Madrid: Siglo XXI, 2008.

CICERÓN, M. T. Sobre la República. Madrid: Gredos, 2002.

COTINO HUESO, L. El derecho a la educación como derecho fundamental. Especial atención a su dimensión social prestacional. Madrid: CEPC, 2016.

DWORKIN, R. Los derechos en serio. Barcelona: Ariel, 2012.

FERRY, L. La revolución transhumanista. Madrid: Alianza Editorial, 2017.

GERRING, J. \& JENOWITZ, J. A Normative Turn in Political Science? Polity, vol. 38, no 1, pp. 101-133.

HABERMAS, J. El Estado de derecho democrático: ¿una unión paradójica de principios contradictorios?. En: Tiempo de transiciones, Madrid: Trotta, 2004, pp.141-165.

HAN, B.-C. (2014). Psicopolítica. Neoliberalismo y nuevas técnicas de poder. Barcelona: Herder.

HUMBOLDT, W. von. Los límites de la acción del Estado. Madrid: Tecnos, 2009.

KANT, I. Fundamentación para una metafísica de las costumbres. En: Kant, Vol. II. Madrid: Gredos, 2010.

KANT, I. La metafísica de las costumbres. Madrid: Tecnos, 2012. 
KAUFMAN-OSBORN, T. Dividing the domain of Political Science: On the Fetishism of Subfields. Polity, vol. 38, nำ 1, 2006, pp. 41-71.

KELSEN, H. ¿Qué es la justicia?. Barcelona: Ariel, 2008.

KELSEN, H. Teoría pura del derecho. Madrid: Trotta, 2011. [Buenos Aires: Eudeba, 2015.]

KIRCHMANN, J. H. von. La jurisprudencia no es ciencia, Madrid: Colección Civitas, 1949.

MARTÍNEZ DE PISÓN, J. El derecho a la educación y la libertad de enseñanza. Madrid: Dykinson, 2003.

MOLINA, I. Conceptos fundamentales de Ciencia política. Madrid: Alianza Editorial, 2013.

PUELLES, M. de. Reflexiones sobre la Política de la Educación en España: una disciplina problemática. New Approaches in Educational Research. Vol. 2, No. 2, Julio 2013, pp. 5055.

PUELLES, M. de. Reflexiones sobre cuarenta años de educación en España o la irresistible seducción de las leyes. Historia y Memoria de la Educación, n. 3, pp. 15-44, 2016.

REEVE, C. D. C. Aristotelian Education. In: RORTY, A. O. (ed.) Philosophers on Education: Historical Perspectives. Oxford: Routledge, 1998, pp. 51-65.

SCHMITT, C. El concepto de lo político. Madrid: Alianza Editorial, 2011.

TORTELlA, G. Los orígenes del siglo XXI. Un ensayo de historia social y económica contemporánea, Madrid: Gadir, 2005.

UNAMUNO, M. de. De la enseñanza superior en España. En: Obras Completas, VIII. Ensayos, Madrid: Fundación José Antonio de Castro, 2007, pp. 1-58.

UNAMUNO, M. de. Sobre el rango y el mérito. Divagaciones. En: Obras Completas, VIII. Ensayos, Madrid: Fundación José Antonio de Castro, 2007, pp. 849-865.

WEBER, M. Economía y sociedad. México: Fondo de Cultura Económica, 2014.

\section{Notas}

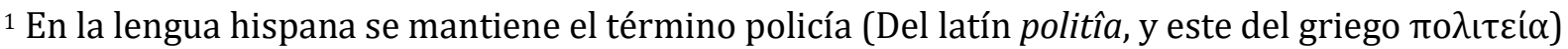
al referirse a la «ordenación de la cosa pública para el mejor gobierno de ciudades y repúblicas» tal como figura en el Diccionario de Autoridades de la Real Academia Española (RAE). La acepción más próxima es la recogida en el Diccionario de la lengua española de la RAE referida al: «Buen orden que se observa y guarda en las ciudades y repúblicas, cumpliéndose las leyes u ordenanzas establecidas para su mejor gobierno.» 

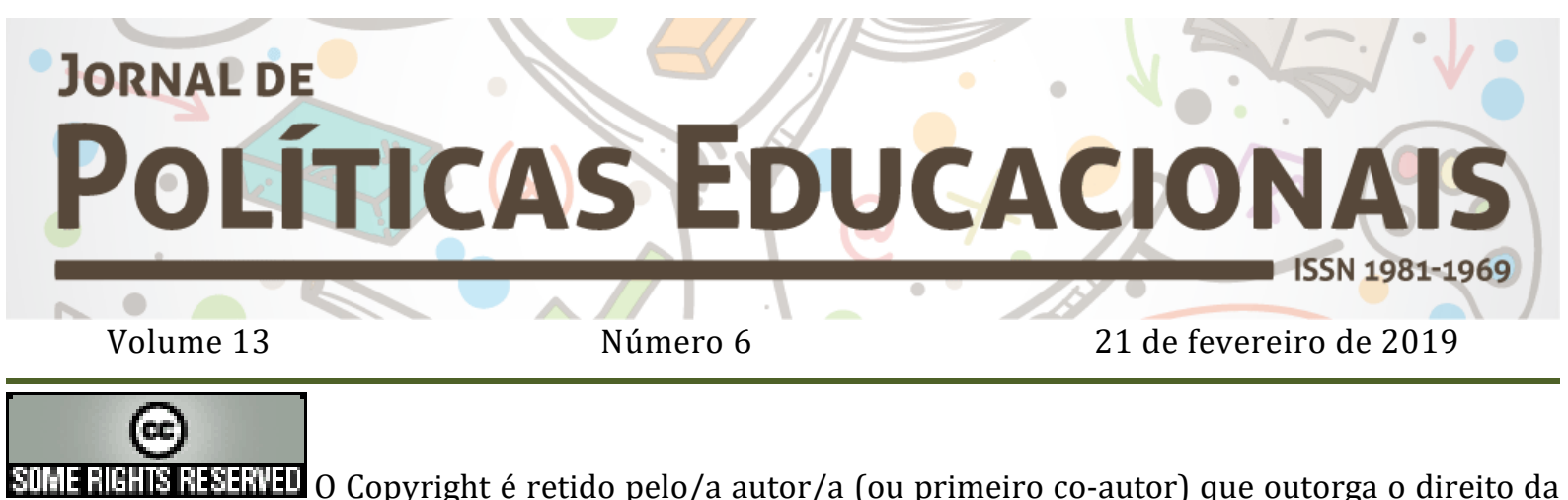

0 Copyright é retido pelo/a autor/a (ou primeiro co-autor) que outorga o direito da primeira publicação ao Jornal de Políticas Educacionais. Mais informação da licença de CreativeCommons encontram-se em http://creativecommons.org/licenses/by-nc-nd/2.5. Qualquer outro uso deve ser aprovado em conjunto pelo/s autor/es e pelo periódico.

Jornal de Políticas Educacionais é uma publicação do Núcleo de PolíticasEducacionaisdo Setor de Educação da Universidade Federal do Paraná - NuPE/UFPR, em consórcio com a Linha de Pesquisa em Políticas Educacionais do Programa de Pós-Graduação em Educação - PPGE/UFPR, que aceita colaboração, reservando-se o direito de publicar ou não o material espontaneamente enviado à redação. As colaborações devem ser enviadas ao NuPE/UFPR, conforme orientações contidas nas páginas do periódico na internet: http://revistas.ufpr.br/ipe.

\author{
Indexação: \\ BBE - Biblioteca Brasileira de Educação (MEC/INEP) \\ Clase (Base de Datos Bibliográfica de Revistas de Ciencias Sociales y Humanidades) \\ Diadorim - Diretório de Política de Acesso Aberto das Revistas Científicas Brasileiras (IBICT) \\ Google Scholar \\ Index Copernicus \\ Portal de Periódicos (CAPES) \\ SER - Sistema Eletrônico de Revistas da Universidade Federal do Paraná (SER/UFPR) \\ Sumários de Revistas Brasileiras (FUNPEC-RP) \\ DRJI - Directory of Research Journals Indexing
}

(Periódico integralmente disponível apenas em via eletrônica)

Jornal de Políticas Educacionais / Núcleo de Políticas Educacionais da Universidade Federal do Paraná -

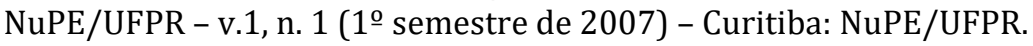

Volume 13, número 6 - Fevereiro de 2019

ISSN 1981-1969

1. Educação - Periódicos. 2. Política Educacional - Periódicos. I. NuPE/UFPR

Comitê Editorial:

Elisângela Scaff (UFPR)

Ana Lorena Bruel (UFPR)

Gabriela Schneider (UFPR)

Conselho Editorial:

Andréa Barbosa Gouveia (UFPR), Ângela Hidalgo (UNICENTRO), Cesar GernominoTello (Universidad Nacional TresFebrero, Argentina),Gladys Beatriz Barreyro (USP), Juca Gil (UFRGS), Jefferson Mainardes 
MAYORAL, J. L. R.; GORDILLO, G. T. Sobre a política como ciência. Educação, desenvolvimento legislativo e transformação das sociedades contemporâneas.

(UEPG), João Ferreira de Oliveira (UFG), Luiz Souza Júnior (UFPB), Marcos Edgard Bassi (UFSC), Regina Maria Michelotto (UFPR), Robert Verhine (UFBA), Rosana Cruz (UFPI), Rubens Barbosa Camargo (USP), Sebastián Donoso Díaz (Universidad de Talca, Chile), Taís Moura Tavares (UFPR), TheresaAdrião (UNICAMP), Vera Peroni (UFRGS).

Créditos e Agradecimentos:

Revisão de Língua Portuguesa, Abstract e Resumen: PROGRAMA DE APOIO ÀS PUBLICAÇÕES CIENTÍFICAS PERIÓDICAS DA UFPR

Arte e diagramação: TIAGO TAVARES (tiagotav@gmail.com)

Jornal de Políticas Educacionais

Universidade Federal do Paraná

Setor de Educação

Núcleo de Políticas Educacionais - NuPE/UFPR

Avenida Sete de Setembro, 2645

$2^{\circ}$ andar, Sala 213

80.230-010 - Curitiba - PR - Brasil

Tel.: 41-3535-6264

jpe@ufpr.br

http://revistas.ufpr.br/jpe 